\title{
HACER LA VERDAD: EL “YO” DE LA CONFESIÓN EN \\ KierkegaArd, Foucault y Derrida ${ }^{1}$
}

\author{
Laura Llevadot \\ Universidad de Barcelona
}

\section{Resumen}

En Tecnologías del Yo (“Cristianismo y confesión”, 1980), Foucault sitúa la confesión como una práctica discursiva cuya finalidad es el control, la constitución y el dominio del yo en las sociedades disciplinarias. De acuerdo con ello, en nuestras sociedades la confesión no puede actuar más que como una sutil forma de interiorización del poder que funciona generando saber sobre uno mismo. En contraste con esta concepción, pero tomándola en consideración, este artículo trata de articular una definición de la confesión como acto de transformación de sí y apertura a la alteridad, llevando a cabo un análisis comparativo de algunos argumentos fundamentales del discurso de circunstancia de Kierkegaard, En ocasión de una confesión, y del texto confesional de Jacques Derrida, Circonfesión.

Palabras clave

Confesión, Kierkegaard, Foucault, Derrida, identidad, alteridad, ética.

\section{Abstract}

In Technologies of the Self ("Christianity and Confession", 1980) Foucault places confession within the discursive practices which are used towards the control, constitution and mastery of the Self in disciplinary societies. According to his argument, in such societies confession cannot act as much more than a subtle but very precise form of interiorizing power through generating knowledge about oneself. On the contrary, in this article I will try to articulate a definition of confession as an act of transformation and opening of the Self to otherness, carrying out a comparative examination of some fundamental reasons behind Kierkegaard's "Occasional Discourse", On the Occasion of a Confession, and Jacques Derrida's confessional text, Circumfession.

Key words

Confession, Kierkegaard, Foucault, Derrida, identity, alterity, ethics.

${ }^{1}$ Recibido: 2 de junio de 2015. Aceptado: 27 de julio de 2015. 
Empecemos por recordar las palabras con las que Foucault cerraba su conferencia de Dartmouth el 24 de noviembre de 1980:

Durante los dos últimos siglos, el problema ha sido: ¿cuál puede ser la fundación positiva para las técnicas del yo que hemos estado desarrollando durante siglos y siglos? Pero quizás haya llegado el momento para nosotros de preguntarnos ¿necesitamos realmente una hermenéutica del yo? Quizás el problema del yo no sea descubrir una fundación positiva. Quizás nuestro problema sea ahora descubrir que el yo no es más que la correlación histórica de la tecnología construida en nuestra historia. Tal vez el problema consista en cambiar estas tecnologías. Y en ese caso, uno de los problemas políticos más fundamentales, en el sentido estricto del término, sea la política de nosotros mismos ${ }^{2}$.

Para Foucault el problema del pensamiento contemporáneo no es ya más ¿qué es el yo? ¿Cuáles son sus fundamentos ontológicos, biológicos o narrativos? sino antes bien ¿cómo y de qué modo se ha construido históricamente este yo que a pesar de todo somos? Que la respuesta acerca de la naturaleza del yo sea esencialista o narrativista no modifica la comprensión metafísica de la identidad tal y como ha sido comprendida "durante siglos", a menos que la pregunta que organice el cuestionamiento sea ¿a través de qué tipo de narratividad, históricamente determinada, hemos construido al yo? De una manera más amplia que excede el componente narrativo, Foucault se pregunta ¿a través de qué tecnologías el sujeto se autoconstituye, mediante qué prácticas -entre las que cabe destacar la "escritura de sî" - el yo moderno da cuenta de sí mismo y se realiza a sí mismo?

Las conferencias y cursos que Foucault impartió durante la década de los 80 marcan un punto de inflexión en su recorrido intelectual ${ }^{3}$. Hasta entonces, Foucault había centrado sus análisis históricos entre los siglos XVII y XIX, y de ellos se derivaba una comprensión del sujeto en términos de producto pasivo de las técnicas de dominación. El resultado de esos análisis era el descubrimiento del sujeto moderno como un sujeto pacientemente

${ }^{2}$ Michel Foucault, "About the Beginning of the Hermeneutics of the Self. Two Lectures at Dartmouth". Political Theory, vol. 21, n. 2, May 1993, p. 223. (La traducción es mía).

3 Ver el comentario de Fréderic Gros en "Situación del curso", M., Foucault, L'herméneutique du sujet. Cours au Collège de France, 1982, Ed. Frédéric Gros, Seuil/Gallimard, 2001; así como el reciente libro de Judith Revel, Foucault, un pensamiento de lo discontinuo, trad. Irene Agoff, Buenos Aires: Amorrotu, 2014. 
constituido por los sistemas de poder y de saber que parecía no poder escapar del control y la normalización más que a través de la locura, el crimen o la literatura, en proximidad con las tesis de Bataille acerca de la transgresión ${ }^{4}$. Sin embargo, a partir de 1980 Foucault inicia unos análisis centrados en la Antigüedad clásica y en el cristianismo primitivo. Su objeto de estudio ya no son los discursos de saber ni las instituciones sino lo que Foucault llamará las "técnicas de sí" o "tecnologías del yo". Se trata de analizar en su continuidad y en su discontinuidad histórica aquellas prácticas a través de las cuales los sujetos se constituyen a sí mismos, ejercitan su subjetividad o practican el "gobierno de sî". Las técnicas de existencia son plurales y diversas, comprenden todas aquellas prácticas que tienen por finalidad descubrir, modificar, gobernar, renunciar o fundar al yo: del autoexamen a los ejercicios corporales, de los ejercicios de rememoración a las lecturas regladas, del retiro a las diversas formas de escritura de sí. En la Antigüedad y en los primeros siglos del cristianismo se observa esta exhortación constante al trabajo del yo sobre sí mismo, y es en este contexto que la "escritura de sí", el relato del yo sobre sí mismo, adquiere una importancia esencial. Pero es necesario señalar que la escritura de sí tiene también una constitución histórica. No siempre el yo se ha relatado a sí mismo de la misma manera. De las cartas de los estoicos a la confesión cristiana se opera una modificación de género narrativo que no atañe solo a la forma literaria sino, más esencialmente, al tipo de relación que el individuo establece consigo mismo. Una de las tesis mayores que se desprenden de los análisis de Foucault en este período es que la confesión cristiana, a diferencia de la escritura de sí que practicaron los antiguos, introduce una tecnología de dominación que somete al individuo al requerir de él una introspección indefinida y una verbalización exhaustiva de la verdad sobre sí mismo. Desde sus orígenes hasta nuestros días la confesión se instituye como una técnica de verbalización de sí que, reinsertada en diferentes contextos por las ciencias humanas modernas, servirá para constituir positivamente un nuevo yo, un tipo de sujeto vigilante de sí mismo, siempre sospechoso de sí, un individuo sin paz obligado a decir la verdad sobre sí mismo, forzado a escudriñar públicamente una interioridad culpabilizada, sea en la sacristía o ante su versión moderna: el diván del psicoanalista.

${ }^{4}$ Michel, Foucault, "Prefacio a la transgresión", en De lenguaje y literatura, trad. Isidro Herrera, Barcelona: Paidós, 1996, pp. 123-142. 
Desde este punto de vista el problema no es si el yo es o no es la historia que se cuenta sí mismo ${ }^{5}$, si se da o no una correspondencia entre lo narrado y lo real, sino que asumido el carácter ficcional de toda identidad es imperioso preguntarse por la tipología de relato de sí que acaba constituyendo al sujeto. Desde la perspectiva foucaultiana la cuestión epistemológica de la correspondencia del relato con la realidad queda desplazada a favor de la perspectiva pragmática según la cual el relato, aún ficticio, tiene efectos de realidad, es decir que determinadas formas de narratividad acaban por conformar una u otra forma de identidad. Y es en este sentido en el que la crítica de Foucault al género narrativo de la confesión me parece relevante y a la vez matizable.

Aun aceptando la perspectiva histórica que plantea Foucault ¿Es necesario considerar ese específico relato de sí en el que consiste la confesión como una práctica de control y creación de un yo sometido? ¿De dónde proviene entonces el interés contemporáneo por la confesión y en concreto, quizás, todas las reinterpretaciones contemporáneas de algunas confesiones célebres, como la de San Agustín o la del mismo Rousseau? ¿Por qué autores tan diversos como Heidegger, Arendt, Derrida, Zambrano o Lyotard han reparado de nuevo en este tipo de relato? ${ }^{6}$. Mi propósito en estas páginas no es responder en términos generales a esta pregunta acerca de la contemporaneidad de la confesión, pero sí tratar de insertar, en el contexto de los análisis de Foucault, el concepto y la práctica de la confesión tal y como Kierkegaard y Derrida la alcanzaron a pensar. Hay en el modo como Kierkegaard y Derrida concibieron la confesión algo que escapa a la definición foucaultiana de la misma como técnica de dominio de sí a través de la verbalización de la verdad, algo que debe ser considerado en virtud de la relación que la confesión mantiene con el perdón, con el acto de pedir perdón antes que con el hecho de relatar la verdad. Desde este punto de vista, según el cual la confesión no consistiría tanto en "decir la verdad"

${ }^{5}$ Daniel Dennett, Conciousness Explained. London: Penguin, Books, 1993.

${ }^{6}$ Ver Martin Heidegger, The Concept of Time (1924). Trad. W. McNeill, Oxford: Blackwell and Cambridge University Press, 1992; Heidegger, Gesamtausgabe: Phänomenologie des religiösen Lebens, vol. 60, section 2: "Augustinus un der Neoplatonismus, Haupteil," p. 175 ss.; Hannah Arendt, Love and Saint Augustine. Ed. Joana Vecchiarelli Scott and Judith Chelius, Chicago: University of Chicago Press, 1996; Jacques Derrida, "Circonfession," en Geoffrey Bennington et Jacques Derrida, Jacques Derrida, Paris: Seuil, 1991; María Zambrano, La confesión: género literario y método, Madrid: Mondadori, 1988; Jean-François Lyotard, The Confession of Augustine, Stanford, Calif.: Stanford University Press, 2000. 
como en "hacer la verdad", este género de creación por la palabra no solo dejaría de ser una tecnología de dominación del yo sino que, en virtud de su apertura al acontecimiento y a la alteridad, permitiría ser pensada como una contribución a aquella "política de nosotros mismos" que el propio Foucault invocaba en 1980 al finalizar su conferencia de Dartmouth.

Con el fin de valorar la apertura y la dimensión ética que entraña la concepción kierkegaardiana y derridiana de la confesión procederé en primer lugar (1) a examinar con mayor profundidad los análisis de Foucault acerca de la confesión; (2) a tratar de establecer la singularidad de la confesión kierkegaardiana que se define en su oposición frontal a cualquier técnica de verbalización de sí, y (3) a señalar la relación entre la confesión y el perdón en Kierkegaard y Derrida.

\section{La confesión como tecnología del yo}

Una de las tesis fundamentales de Foucault es que la diferencia entre la antigüedad greco-romana y el cristianismo no puede ser comprendida como el pasaje de una cultura liberal y tolerante a una cultura, la cristiana, opresiva y austera. La diferencia radicaría en todo caso entre dos formas de austeridad que son a la vez dos modos diversos de relación del yo consigo mismo. Basta comparar las formas de escritura de sí antigua y cristiana para apreciar estas dos formas de austeridad y de gobierno de sí que corresponden a dos principios bien diferenciados, el principio éticoestético "cuida de ti mismo" que se percibe en las cartas, por ejemplo, de Séneca, y el principio platónico-cristiano "conócete a ti mismo", al que correspondería el ejercicio de la confesión. No se trata, claro está, de menospreciar el papel del conocimiento de sí en la cultura antigua que, por otra parte, está no solo en la máxima délfica que todos recordamos sino por doquier de los textos canónicos de dicha tradición, pero sí de hacer hincapié en el hecho de que el conocimiento de sí no es el objetivo principal de la cultura antigua: "Ha habido una inversión entre la jerarquía de los dos principios de la Antigüedad, "cuida de ti mismo" y "conócete a ti mismo" En la cultura grecorromana el conocimiento de sí se presentaba como la consecuencia de la preocupación por el sí. En el mundo moderno, el conocimiento de sí constituye el principio fundamental" 7 . Los análisis de Foucault, especialmente los llevados a cabo en los cursos del Collège de

${ }^{7}$ Michel Foucault, Technologies of the Self. A seminar with Michel Foucault. Amherst (USA): The University of Massachusetts Press, 1988, p. 22. 
France de 1981-1982, muestran cómo para los antiguos la verdad es algo exterior a la subjetividad que el individuo debe aprender y recordar. La utilidad de las cartas, por ejemplo, en las que el sujeto rememora todo lo que ha hecho durante el día en su más mínimo detalle, no es descubrir la verdad del propio yo sino valorar la distancia entre lo que se ha hecho efectivamente y lo que se debería haber hecho, entre la práctica de la vida cotidiana y la verdad aprendida de los maestros que el individuo debe asimilar para llevar una vida recta:

Para Séneca no se trata de descubrir la verdad en el sujeto, sino de recordar la verdad, de recobrar una verdad que ha sido olvidada. En segundo lugar, el sujeto no se olvida a sí mismo, ni a su naturaleza, origen o su afinidad sobrenatural, sino las reglas de conducta lo que tenía que haber hecho ${ }^{8}$.

Por el contrario el cristianismo introduce un elemento completamente diferente, el cristianismo es "una religión confesional" . Esto significa que el cristianismo, a diferencia de las escuelas paganas, introduce el imperativo del conocimiento de sí, la obligación de descifrar la verdad sobre uno mismo. No se trata ya de acceder y asimilar una verdad exterior al sujeto, sino de revelarse uno mismo en su verdad y solo así alcanzar la pureza necesaria. El cristianismo implanta la exigencia de purificación a través del descubrimiento de los pecados, la obligación de publicar y verbalizar el error que el individuo es. Pero cuando Foucault analiza esta nueva tecnología del yo en las prácticas de la vida monástica de los primeros cristianos descubre dos formas bien diferenciadas de llevar a cabo esta purificación: la exomologesis y la exagoreusis. La exomologesis no es una conducta textual sino un acto de reconocimiento dramático del estatuto del penitente. Se trata a menudo de formas teatralizadas de autocastigo en los que el penitente alcanza la verdad al mostrarse a sí mismo como pecador. Tertuliano hablará a este propósito de una publicatio sui, de la necesidad de publicarse a sí mismo. Pero esta publicidad del yo no pasa tanto por la confesión de los pecados, de los actos cometidos, cuanto por el reconocimiento del propio estatus de pecador, sin que sea necesario decir el pecado. Foucault se referirá a la práctica de la exomologesis como la "tentación ontológica" del cristianismo puesto que lo que se espera de ella es la revelación de la condición misma del yo como

${ }^{8}$ Michel Foucault, Technologies of the Self, op. cit., p. 34.

${ }^{9}$ Michel Foucault, Technologies of the Self, op. cit., p.40. 
individuo pecador. Por el contrario la exagouresis es, al parecer de Foucault, la "tentación epistemológica" del cristianismo ${ }^{10}$ en la medida en que exige hacer aparecer la verdad a través del análisis de los pensamientos, a través de la verbalización pormenorizada no solo de lo sucedido sino especialmente de lo pensado y sentido acerca de ello. El análisis de los pensamientos, sentimientos, tentaciones y deseos ocultos del yo es lo que constituye propiamente la confesión, es decir, la exagouresis. Es con esta práctica de verbalización y análisis que se inicia la hermenéutica del sujeto, el análisis interpretativo del yo que se acabará imponiendo en la modernidad en un contexto secularizado:

Mi hipótesis es que en referencia a estas dos técnicas la segunda, la verbalización, se vuelve más importante. Desde el siglo XVIII hasta el presente, las técnicas de verbalización han sido reinsertadas en un contexto diferente por las llamadas ciencias humanas para ser utilizadas sin que haya renuncia al yo, pero para constituir positivamente un nuevo yo. Utilizar estas técnicas sin renunciar a sí mismo supone un cambio decisivo $^{11}$.

Estamos pues ante dos grandes tesis que se desprenden de los análisis del último Foucault y que atañen en su esencia al papel de la confesión como relato y técnica de sí en la cultura occidental. En primer lugar, el principio cristiano "conócete a ti mismo" se habría impuesto en nuestra cultura sobre el principio ético-estético de los antiguos del "cuida de ti mismo". En segundo lugar el precepto del conocimiento de sí se habría concretado a través del triunfo histórico de la exagoreusis sobre la práctica de la exomologesis, es decir, la técnica y la obligación de la verbalización de raíz cristiana habría sobrevivido en nuestra cultura más allá de la manifestación dramática de sí que supone la exomologesis. La confesión, por lo tanto, como tecnología del yo consistente en el relato verdadero de sí que obliga al individuo a descifrarse, examinarse y analizarse constantemente a sí mismo seguiría presente en nuestras sociedades contemporáneas si bien se ha borrado de esta práctica narrativa toda renuncia a sí mismo y todo autosacrificio. En su forma secularizada la confesión tiene por finalidad constituir positivamente un yo en permanente situación de autoanálisis, condenado a saber sobre sí y obligado a decir la verdad acerca de sí mismo. Puede decirse, en último

${ }^{10}$ Michel Foucault, "About the Beginning of the Hermeneutics of the Self. Two Lectures at Dartmouth", op. cit., p. 222.

${ }^{11}$ Michel Foucault, Technologies of the Self, p. 40. 
término, que la tentación epistemológica del cristianismo ha sobrevivido a través de la confesión a su tentación ontológica tanto como a su constitución ético-estética, tal y como era formulada por los antiguos. Es por ello que aún hoy seguimos preguntándonos acerca del fundamento positivo y de la realidad de este yo que para Foucault no es más que el producto de estas técnicas de transformación de sí.

\section{Decir la verdad, hacer la verdad}

¿Puede la obra de Kierkegaard, en virtud de su compleja articulación entre la escritura y la reflexión en torno al yo, ser insertada en esta tradición de la hermenéutica del sujeto que Foucault descubre? ¿Puede decirse que la obra de Kierkegaard ha contribuido de algún modo al establecimiento de esta cultura del yo caracterizada por el autoanálisis y la verbalización de sí? ¿Son las estrategias estilísticas que Kierkegaard pone en funcionamiento variaciones de ciertas técnicas de escritura de sí que tienen por finalidad constituir positivamente un yo y por lo tanto dominarlo?

En primer lugar hay que empezar por reconocer que si alguien ha denunciado radicalmente la posibilidad de decir la verdad sobre uno mismo, en su obra y en su vida, este ha sido sin duda Kierkegaard: "Tras mi muerte nadie hallará en mis papeles la más mínima información (este es mi consuelo) acerca de lo que realmente ha llenado mi vida; nadie encontrará la inscripción en mi ser más interno que lo pueda interpretar todo" ${ }^{12}$. A pesar de todo lo escrito por Kierkegaard, a pesar del carácter aparentemente biográfico de muchos de sus textos, a pesar de la existencia de sus voluminosos diarios y papeles que podrían alimentar la hipótesis de una escritura verídica de sí, Kierkegaard advierte que en ningún lugar de esta escritura prolífica y diversa -ni siquiera en sus diarios- podrá hallarse la verdad de su existencia, la narración que lo explicaría todo, que ofrecería finalmente el sentido de esta co-implicación tan radical entre la vida y la obra que Kierkegaard encarnó. Kierkegaard mantiene abierta la posibilidad de que el relato no solo no diga la verdad de la existencia, sino de que la narración misma esté justificada en la medida en que la oculta. Se escribiría entonces no para decir la verdad sino para encubrirla. Esta sería quizás una de las lecciones que Kierkegaard nos legaría si nos decidiéramos a seguirlo hasta el final de esta andadura de la ocultación.

${ }^{12}$ Søren Kierkegaard, JP, 5.645 /Pap. IV, A 85 (1843). 
Por otra parte, que la verdad sea algo que deba mantenerse oculto es un principio que se manifiesta también al nivel de la obra misma, ya sin relación alguna con la vida empírica del autor. Kierkegaard desautoriza toda pretensión de hallar el texto que explicaría el sentido interno de la obra, que ofrecería la llave hermenéutica para leer y dotar de un sentido homogéneo la multiplicidad heterogénea y contradictoria que constituye la polifonía textual de su producción. Ni siquiera él mismo se arroga el derecho de captar plenamente el sentido interno de su creación, y tampoco Punto de vista, el texto en que Kierkegaard se autoproclama autor religioso, puede ser ya considerado el texto privilegiado para emprender una lectura significativa de la totalidad de la producción ${ }^{13}$.

Pero alguien podría estar tentado de pensar que quizás esta verdad no deba buscarse en la vida de Kierkegaard mismo ni en la coherencia interna de la obra, que tal vez Kierkegaard no buscó tanto la correspondencia entre la verdad de su yo empírico y el relato, cuanto hacerse a sí mismo verídico en la obra, construir su subjetividad en el acto mismo de escribir. Se ha publicado mucho acerca del carácter productivo de la escritura kierkegaardiana, y tal vez haya sido Joakim Garff quien haya llevado más lejos esta hipótesis: Kierkegaard se habría producido a sí mismo ${ }^{14}$, su vida habría sido transfigurada por la escritura, tal y como él mismo había fantaseado al dibujar la figura de un improbable escritor: "Situación: Una persona quiere escribir una novela en la que uno de los personajes se vuelve loco; durante el proceso de composición él mismo se vuelve gradualmente loco y acaba la novela en primera persona" ${ }^{15}$. Sin embargo hay que tener en cuenta los límites del poder material de la ficcionalidad que el mismo Garff reconoce cuando escribe:

Únicamente en la ficción, la producción textual del yo, puede el Kierkegaard que es -como él mismo admite- antes y tras la escritura 'una ausencia', devenir presente. Pero solo presente, por supuesto,

13 Sobre esta cuestión ver el imprescindible análisis de Joakim Garff "The Eyes of Argus: The Point of View and Points of View on Kierkegaard's Work as an Author", Kierkegaard: A Critical Reader, ed. Jonathan Rée y Jane Chamberlain, Oxford: Blackwell Publishers, pp. 75-102, y Dolors, Perarnau, "El punto de vista sobre mi actividad como escritor: Tan solo un punto de vista”, Kierkegaardiana, n. 23, pp. 96-112.

${ }^{14}$ Joakim Garff, "Produire fut ma vie"-problèmes et perspectives de la biographie de Kierkegaard, Kierkegaard aujourd'bui. Recherches kierkegaardiennes au Danemark et en France, Editées et rédigées par Jacques Caron, Odense University Press, 1998, pp. 17-33.

${ }^{15}$ Søren Kierkegaard, JP 5249/ Pap II, A 634. 
como escritor. Tan pronto como lee su biografía, Kierkegaard se convierte de nuevo en una ausencia ${ }^{16}$.

La posibilidad de una producción textual del yo debe ser limitada, entonces, a Kierkegaard como autor. Esto significa, no solo que el texto no se corresponde con la realidad empírica del sujeto llamado Søren Aabye Kierkegaard, sino que lo que el texto produce es al "Kierkegaard-autor", a un sujeto ficticio que solo adviene posible en el acto mismo de escritura y de lectura. En un sentido análogo a la definición que Foucault da de la figura del autor, el Kierkegaard-autor no sería entonces un sujeto empírico del cual la escritura daría cuenta, sino una función del texto que solo adviene posible a través del acto de lectura: "el autor no es una fuente infinita de significación que completa una obra; el autor no precede a la obra; él es un cierto principio funcional a través del cual, en nuestra cultura, se limita, se excluye y se elige" 17 .

Kierkegaard fue plenamente consciente del carácter ficticio de toda escritura y de todo lenguaje. De hecho explotó hasta sus últimas consecuencias esta condición interna de la textualidad. Trató de mostrar no solo que la narración no se corresponde en modo alguno con la realidad, sino que la narración produce su propia realidad, una realidad ficticia, ideada, que puede ser coherente o no, que puede constituir un autor bien definido o una personalidad polifónica y contradictoria. La pseudonimia muestra bien la complejidad de este autor que se desautoriza a cada momento como ostentador del sentido del texto en cuanto introduce la perspectiva crítica dentro de la propia producción textual. En esta medida puede decirse que el relato, para Kierkegaard, no tiene por función decir la verdad, una verdad previa al acto mismo de escritura, sino hacer la verdad, producirla, incluso la verdad ficticia del autor.

Si esto es así, si seguimos hasta el final los análisis de Garff y admitimos el carácter ficcional de la narratividad kierkegaardiana, habría que preguntarse de dónde proviene el interés de Kierkegaard por la confesión. ¿No es una contradicción pensar que alguien que construyó una trama tan compleja de ficciones creía sin embargo en la posibilidad de un relato verdadero de sí, en la posibilidad y la necesidad de decir la verdad sobre uno mismo? ¿Habrá

${ }^{16}$ Joakim Garff, “The Eyes of Argus”, op. cit. p. 91.

${ }_{17}$ Michael Foucault, "What is an Author?", Aesthetics, method and epistemology, edited by James D. Faubion, trad. Robert Huley, London: Penguin Press, 1998, p. 221. 
que invocar aquí una sobredeterminación religiosa que acabe por dar la razón a esa ficción textual que es el Synspunkt?

Para responder esta pregunta habría que establecer una segunda distinción entre las funciones del relato, no solo la diferencia entre "decir la verdad" y "hacer la verdad", sino entre dos modos bien diversos de "hacer la verdad", uno de los cuales correspondería a la ficción romántica y el otro a la confesión propiamente dicha. Hemos afirmado que la narración kierkegaardiana desmiente una y otra vez la posibilidad de decir la verdad sobre uno mismo, en este sentido nadie como Kierkegaard ha arruinado tan radicalmente la posibilidad de "decir la verdad" sobre sí, la posibilidad misma de la autobiografía. Por el contrario, podría decirse que la producción literaria de Kierkegaard si bien no dice la verdad de un sujeto pre-existente, sí produce en su propio devenir al sujeto-autor, y estaríamos entonces inclinados a pensar que si bien el relato no "dice la verdad" sí "hace la verdad". Ahora bien, hay que extremar las precauciones en este punto del análisis que fácilmente convertiría a Kierkegaard en el romántico que él quiso siempre denunciar y respecto al cuál trató de tomar sus distancias. Una de las críticas iniciales que Kierkegaard dirige a la poesía romántica es precisamente el hecho de que esta solo es capaz de reconciliarnos con lo real en la medida en que reinventa otra realidad. En toda poesía romántica hay un escapismo que hace del relato una invención necesaria para hacer la vida soportable pero que en modo alguno aporta la inexcusable reconciliación con lo real: "Si nos preguntamos, en efecto, qué es la poesía, podemos caracterizarla de manera totalmente general como una victoria sobre el mundo; es mediante una negación de la realidad imperfecta como la poesía abre a una realidad superior, ensancha y despliega lo imperfecto en dirección a lo perfecto" 18 . De hecho, esta reconstrucción ficticia de lo real a través de la narración que Kierkegaard critica puede hallarse en ciertas formas modernas de confesión, y de modo paradigmático en las Confesiones de Rousseau, sobre las cuales se ha llegado a afirmar que "Rousseau en cierto modo creó a Jean-Jacques, como sujeto que podía descubrir in su subjetividad una huída, una alternativa, a sus condiciones de emergencia"19. Para escapar de esta circularidad del relato que o bien pretende ingenuamente decir

${ }^{18}$ Søren Kierkegaard, Sobre el concepto de ironía, en Escritos S. Kierkegaard, trad. Darío González, Madrid: Trotta, p. 316 / SKS I, 330. Para un análisis de la crítica a la poesía romántica en On the concept of Irony ver: Brian Soderquist, The Isolated Self, Copenhague: Reitzels, C.A., 2007.

${ }^{19}$ Huck Gutman, "Rousseau's Confessions: A Technology of the Self”, Technologies of the Self. A Seminar with Michel Foucault, op. cit., p. 113. 
una verdad preexistente o bien crea una verdad ficticia, un paisaje interior tanto más habitable cuanto menos se asemeje a lo real, habría que poder considerar otro concepto de verdad que no se limite a la correspondencia, una verdad entendida como acontecimiento, y en el caso concreto de la confesión, como acontecimiento de transformación de sí antes que como análisis y verbalización del yo. Veamos en qué pueda consistir esta verdad y este acontecimiento que la confesión -según Kierkegaard, pero también según Derrida- nos permitiría pensar.

\section{La confesión como acontecimiento}

En septiembre de 2001, días después del atentado de las torres gemelas, tuvo lugar un congreso acerca de la Confesión en la Villanova University en el que participó Derrida. Alguien presuntamente tan alejado de un concepto de verdad como adecuación, que tanto había criticado la noción constatativa de la verdad ${ }^{20}$, había escrito sin embargo años antes unas confesiones a las que llamó Circonfession ${ }^{21}$, en clara alusión a la marca involuntaria que inscribe a alguien desde niño en una comunidad, en este caso la judía. En su intervención Derrida da las claves para comprender en qué consiste la confesión que sin candidez alguna emprendió tiempo atrás, y para situar bien la cuestión Derrida empieza por señalar que en la confesión el problema no es la verdad sino el acontecimiento (l'événement). Hay que seguir a Derrida cuando plantea que la confesión no tiene por objeto "decir la verdad" sino "hacer la verdad", donde hacer la verdad no significa ya tanto la producción libre y autónoma de un sujeto activo cuanto el acontecimiento que se sigue del acto mismo de confesarse. En palabras de Derrida:

Cuando se pide perdón, cuando alguien se confiesa (...) no es cuestión de verdad, al menos no es cuestión de la verdad constatativa. Cuando pido, cuando me confieso, no estoy relatando un hecho. Puedo matar a alguien. Puedo estrellar un avión y después explicarlo; no es una confesión. Llega a ser confesión únicamente cuando pido perdón y, de acuerdo con la tradición, cuando prometo arrepentirme, esto es, mejorar, amar, transformar mi odio en amor, transformarme a mi mismo, y hacerlo con amor. No es una cuestión de conocimiento. No

${ }^{20}$ Jaques Derrida, De la gramatología, trad. O. Del Barco y C. Ceretti, Mexico DF Buenos Aires: Siglo XXI, 2003, p. 16 y ss. Seuil, 1991.

${ }^{21}$ Jacques Derrida, Circonfession, en Bennington, Geoffrey, Jacques Derrida, Paris: 
se trata de hacer saber al otro lo que ha ocurrido, sino de cambiar, de transformarse uno mismo. Quizás sea esto lo que Agustín llamaba "hacer la verdad". No decir la verdad, no informar -Dios ya lo sabe todo- sino bacer la verdad, producirla ${ }^{22}$.

Quizás no haya ningún otro texto contemporáneo en el que se manifieste de manera tan clara y rotunda el estatuto de la confesión en el mismo sentido en que Kierkegaard lo planteó. Una confesión en la que no haya petición de perdón no es en absoluto una confesión. Sin reconocimiento de culpabilidad, sin petición de perdón, el que se confiesa se limita a relatar unos hechos, y ese relato puede ser entonces susceptible de ser verdadero o falso. Pero en la confesión no hay verdad alguna a relatar susceptible de ser constatada, sino que aún en la ausencia de todo contenido concreto, la verdad de la confesión es performativa, es lo hecho por la confesión. La diferencia entre la autobiografía y la confesión solo aparece de veras allí donde la confesión se desentiende de su estructura onto-teológica que subsume la narración de sí al qué del relato, al contenido, al secreto a revelar. Ya en 1845, Kierkegaard advertía de este carácter performativo de la confesión cuya finalidad no era tanto decir la verdad del pecado cuanto llevar a cabo una transformación del yo:

(...) buscar significa que él busca, que él mismo se transforma. No es preciso que halle el lugar en el que está lo buscado, pues está junto a él; no es preciso que halle el lugar en el que está Dios, no es preciso que se esfuerce por llegar allí, pues Dios está junto a él, totalmente próximo, próximo en todas partes, omnipresente a cada instante, sino que es preciso que se transforme para llegar a ser él mismo el lugar en el que Dios verdaderamente está23.

En este fragmento del discurso En ocasión de una confesión Kierkegaard hace hincapié en el mecanismo transformador de la confesión. La confesión no consiste en relatar la verdad sobre sí mismo como si esta fuera un qué previo a representar por la narración, pero tampoco consiste en buscar la verdad como un elemento exterior al propio sujeto que la inquiere, y muchísimo

${ }^{22}$ Jacques Derrida, "Composing Circumfession", Augustine and Postmodernism. Confessions and Circumfession. Ed. John D. Caputo y Michael J. Scanlon, Bloomington e Indianapolis: Indiana University Press, 2005, p. 23. (La traducción es mía).

23 Søren Kierkegaard, "En ocasión de una confesión”, en Tres discursos para ocasiones supuestas, Escritos Soren Kierkegaard, vol. 5, trad. Darío González, Madrid: Trotta, 2010, p. 404 / SKS V, 403-404. 
menos algo que el sujeto pudiera crear. La verdad no es un "qué" que deba ser relatado ni buscado ni creado, es en cualquier caso aquello que el sujeto hace al transformarse a sí mismo: "Cuando se supone que lo que se busca está dado, buscar significa que el que busca, que él mismo se transforma, y así llega a ser el lugar en que lo buscado puede estar verdaderamente" 24 . Este segundo sentido de "hacer la verdad" que caracteriza la confesión desborda entonces toda concepción constatativa de la misma y la aparta de la dimensión epistemológica que denunciaba Foucault. La confesión es tal porque se dirige a alguien, a Dios, al otro, pero precisamente el carácter absoluto de este otro evita que la confesión recaiga en el mero relato de la verdad. Dios sabe ya todo, sabe todo los pecados y no necesita que le sean relatados. "¿Por qué nos confesamos a Dios, si él sabe ya todo de nosotros?”, reza la pregunta de Sant Agustín que Derrida gusta recordar ${ }^{25}$. La confesión no tiene nada que ver con el saber, no es una cuestión de saber ni de relato de hechos pasados, sino un acontecimiento. De ahí que Kierkegaard se obstine tanto en recordar que "el reconocimiento del pecado no es meramente una enumeración de todos los pecados particulares" ${ }^{26}$, ni tampoco el reconocimiento del pecado como característica universal de la especie porque entonces el pecado deviene objeto de teorización y el que se confiesa se reduce a su papel de mero observador abstracto. La insistencia de Kierkegaard en este texto acerca del "instante de la decisión" 27 en el cual alguien se decide a confesarse proviene de que el objeto de la confesión no es el análisis y el relato de la verdad del yo sino el acto de arrepentimiento, la declaración de uno mismo como culpable, la petición de perdón y por lo tanto la promesa implícita de transformarse uno mismo para ser el lugar en el que la verdad adviene. "Arrepentirse de una universalidad sin contenido es una contradicción, como lo sería dedicarle la pasión más profunda a lo superfluo; pero fijar el arrepentimiento a algo particular es arrepentirse por cuenta propia, no ante Dios" 28 . Que no se fije el arrepentimiento en algo particular exonera la confesión de toda similitud con la biografía y el relato de sí, y que el arrepentimiento no pueda tener carácter de universalidad indica la estructura necesariamente singular e individual de toda confesión.

${ }^{24}$ Søren, Kierkegaard, Ibíd., p. 406 / SKS V, 406.

${ }^{25}$ Jacques Derrida, Circonfession, op. cit., p. 19.

${ }^{26}$ Søren Kierkegaard, ibíd., p. 411 / SKS V, 411.

${ }^{27}$ Søren Kierkegaard, ibíd., p. 416 / SKS V, 416.

${ }^{28}$ Søren Kierkegaard, ibíd., p. 413 / SKS V, 413. 
Desde este punto de vista, la confesión tal y como Kierkegaard y Derrida la comprenden tendría poco que ver con la exagoreusis analizada por Foucault. Alejada de toda tentación epistemológica del cristianismo la confesión no tendría ya por función hacer aparecer la verdad de lo sucedido, ni llevar a cabo un autoanálisis para desvelar los secretos del yo. Podría pensarse que en su dimensión de acontecimiento discursivo la confesión estaría más cerca del reconocimiento dramático del estatuto del penitente en el que consistía la técnica de la exomologesis que en la verbalización de sí. Pero lo cierto es que si subrayamos el carácter performativo de la confesión, esta práctica discursiva desbordaría el papel regulador que Foucault asignaba al principio del "conócete a ti mismo". También en este texto, como en tantos otros de su obra, Kierkegaard arremete contra el saber: "¿acaso no se engaña también el que ha llegado a saber mucho sin apropiarse de nada en absoluto? (...) "hay un espejismo del saber que fascina al alma, que hay una suficiencia que consiste en saber -pero en la que uno es engañado" 29 . Es de suponer que también el conocimiento de sí debe ser relativizado desde el punto de vista de la confesión, porque se trata de "hacer la verdad" -esto es, de pedir perdón, de arrepentirse- no de conocerla.

Pero queda todavía una cuestión por aclarar: ¿por qué sería necesario pedir perdón? ¿Por qué confesarse? ¿No pertenece igualmente la confesión a una cultura del yo empeñada en culpabilizar al sujeto aun sin exigirle la verbalización de la verdad sobre sí mismo? ¿No seguiría siendo de este modo la confesión una tecnología de sumisión y control del yo? ¿Por qué la confesión entendida como técnica de existencia debería ser digna de ser considerada?

\section{Perdón y alteridad}

Si se admite que lo que constituye y define a la confesión no es la verbalización de la verdad acerca del yo, tal y como planteaba Foucault, sino el acontecimiento discursivo que consiste en pedir perdón, y por lo tanto en prometer implícitamente una transformación de sí, entonces hay que afirmar la estructura heterológica de la confesión, el hecho estructural de que la confesión siempre se dirige a otro a quien se solicita el perdón, se sepa o no de su existencia efectiva ${ }^{30}$. Siempre es ante un "tú" que el "yo" se

\footnotetext{
${ }^{29}$ Søren Kierkegaard, ibíd., p. 402 / SKS V, 402.

${ }^{30}$ Ver a este respecto las reflexiones de J. Caputo acerca de la plegaria en J.D. Caputo "Shedding Tears Beyond Being", Augustine and Postmodernism: Confessions and Circum-
} 
confiesa, no para afirmar su identidad en el reconocimiento y el relato de sus faltas, sino para prometer (a otro) una transformación, es decir, para abrirse a una discontinuidad a la que le fuerza la alteridad del otro. La confesión, lejos de encerrar al sujeto sobre sí mismo, abre a la alteridad, ya que todo perdón implica la virtualidad del otro, se dirige a un tú, que en Kierkegaard es sin duda Dios, pero que puede ser leído en los términos derridianos de un "cualquier radicalmente otro".

De hecho, la diferencia entre la autobiografía y la confesión puede cifrarse en la distancia que separa a la formulación kantiana del yo en la Antropología en sentido pragmático y la definición heterológica del yo que Kierkegaard plantea en La enfermedad mortal. Allí donde Kant cifra la peculiaridad del hombre frente a la cosa en la capacidad para "poder tener un yo en su representación”, esa unidad de conciencia que acompaña a todas las representaciones, allí Kierkegaard hace depender la realidad del yo de su relación con otro: "El yo del hombre es una relación que se relaciona consigo misma y que en tanto se relaciona consigo misma, está relacionándose con un otro" ${ }^{31}$. Esta es precisamente la estructura de la confesión, un relato en el que el yo se relaciona consigo mismo y al relacionarse consigo se relaciona con otro -a través del perdón, habrá que añadir. Mientras que el "yo" que Kant hace acompañar todas las representaciones, y ofrecer así la unidad del sujeto moral, permite la fundación de ese "animal autobiográfico" que es el hombre -puesto que el resto de los animales estarían privados de esa "relación autobiográfica consigo mismo" ${ }^{32}$, el yo atravesado por una alteridad radical tal y como es concebido por Kierkegaard en $\mathrm{La}$ enfermedad mortal permite pensar al hombre como animal confesional, como ese animal capaz de pedir perdón (sin prejuzgar aquí si el resto de los animales pueden o no hacerlo). Al concebir el yo como una relación que al relacionarse consigo misma se relaciona con otro Kierkegaard abre la posibilidad de pensar la confesión más allá de su condición de tecnología del yo fundadora de identidad. La confesión, en cuanto técnica de existencia -aún si seguimos aquí la terminología foucaultiana-, abre el yo a la alteridad que le es propia. El acontecimiento en el que consiste el acto de la confesión, ese acontecimiento que, como afirma Bennington es siempre

fession, ed. John D. Caputo y Michael J. Scalon, Bloomington: Indiana University Press, 2005, pp. 95-114.

${ }^{31}$ Søren Kierkegaard, La enfermedad mortal, trad. Demetrio G. Rivero, Madrid: Guadarrama, 1969, p. 48 / SKS XI, 130.

${ }^{32}$ Jacques Derrida, El animal que luego estoy si(gui)endo, trad. C. de Peretti y C. Rodríguez, Madrid: Trotta, 2008, p. 114. 
más que el acontecimiento confesado ${ }^{33}$, introduce la petición de perdón como condición existencial del sujeto. La culpa no le viene a uno de fuera, ni siquiera depende de lo que se haga, está implícita en el hecho mismo de existir, de ahí que la particularidad del pecado a confesar sea lo de menos. "No se trata de acrecentar la culpa para que Dios se vuelva más grande, pero sí de acrecentar el conocimiento de la culpa" ${ }^{4}$, dirá Kierkegaard en "En ocasión de una confesión”, y toda la gradación dialéctica de la última parte del Post-scriptum se organizará en torno a esta "conciencia de la culpa" que sirve allí de bisagra entre uno y otro modo de existencia.

Pero ¿de qué habríamos de sentirnos culpables? ¿Por qué deberíamos pedir perdón? ¿No sería mejor instalarse en una concepción nietzscheana de la existencia que afirme la inocencia y la alegría por encima de toda culpabilidad? Es probable que aquí se cifre la distancia que separa al Foucault que defendía una cierta "estética de la existencia” de raíces greco-romanas del último Derrida para quien la cuestión del perdón devendrá esencial. Para Derrida se pide perdón siempre que, por ejemplo, se escribe -algo de lo que Kierkegaard fue plenamente consciente. Perdón por dejar una traza a otro que no sé ni sabré nunca quien es, por pensar que lo escrito vale el tiempo que el otro perderá en leerlo, por escribir en lugar de ser, por abandonar la ética, el matrimonio, la realidad -en terminología kierkegaardiana- a favor de la ficción del relato. Se pide también perdón por sacrificar al otro, y al otro del otro, por atender solo a los míos y abandonar así a todos los otros a quienes dejamos morir. Pero sobre todo se pide perdón por ser-ahí (por Dasein), según la célebre fórmula heideggeriana, por estar ahí siempre en lugar del otro, en el lugar del que murió en Auschwitz o del hermano gemelo que no llegó a vivir: "lloro desde mi madre por el niño a quien sustituyo" 35 , o por "no haber hecho lo suficiente para salvar judíos" 36 , o por no haber hecho lo suficiente para salvarse uno mismo ${ }^{37}$.

En cualquiera de los casos esa escritura confesional atravesada de parte a parte por la alteridad no tiene ya por función establecer al yo en su verdad positiva. A pesar de la enorme distancia que separa las posiciones aquí analizadas quizás sea posible leer en los trabajos acerca de la confesión llevados a cabo por Kierkegaard y Derrida justamente aquello que Foucault

${ }^{33}$ Geoffrey Bennington "Time-for the Truth" en Augustine and Postmodernism, op. cit., p. 62.

${ }^{34}$ Søren Kierkegaard, "En ocasión de una confesión”, op. cit., p. 409 / SKS 409.

${ }^{35}$ Jacques Derrida, Circonfession, p. 114.

${ }^{36}$ Ibíd., p. 289.

${ }^{37}$ Ibíd., p. 289. 
demandaba al cerrar su conferencia en Dartmouth: no ya la interpelación acerca del conocimiento del yo, ni en términos ficcionales ni en términos realistas, sino una "política de nosotros mismos". Tal vez estemos empezando a cambiar esas tecnologías que han construido nuestra identidad cuando dejemos de cuestionarnos acerca del yo desde una perspectiva epistemológica y tratemos de pensarlo a partir de su condición ética, de su posición de apertura a la alteridad. Es aquí donde cuestiones como la confesión o el perdón devienen relevantes para la ética contemporánea y quizás también para esa "política de nosotros mismos" que invocaba Foucault.

\section{Bibliografía}

Kierkegaard, Søren, "En ocasión de una confesión”, en Tres discursos para ocasiones supuestas, Escritos Søren Kierkegaard, vol. 5, trad. Darío González, Madrid : Trotta, 2010.

Kierkegaard, Søren, Journals and papers, ed. y trad. Howard V. Hong y Edna H. Hong, Bloomington: Indiana University Press, 1967.

Kierkegaard, Søren, Søren Kierkegaards Skrifter, udgivet af Søren Kierkegaard forskningscenteret ; [redaktion, Niels Jørgen Cappelørn ... et al.], Copnehaguen: Gads Forlag, 1997.

Kierkegaard, Søren, La enfermedad mortal, trad. Demetrio G. Rivero, Madrid: Guadarrama, 1969.

Kierkegaard, Søren, Sobre concepto de ironía, en Escritos Søren Kierkegaard, trad. Darío González, Madrid: Trotta, p. 316

Arendt, Hannah, Love and Saint Augustine, ed. Joana Vecchiarelli Scott y Judith Chelius, Chicago: University of Chicago Press, 1996.

Caputo, J. D., "Shedding Tears Beyond Being", Augustine and Postmodernism: Confessions and Circumfession, ed. John D. Caputo y Michael J. Scalon, Bloomington: Indiana University Press, 2005.

Dennett, Daniel, Conciousness Explained, London: Penguin Books, 1993.

Derrida, Jacques, "Circonfession," en Geoffrey Bennington et Jacques Derrida, Jacques Derrida, Paris: Seuil, 1991. 
Derrida, Jacques, "Composing Circumfession", Augustine and Postmodernism. Confessions and Circumfession. Ed. John D. Caputo y Michael J. Scanlon, Bloomington e Indianapolis: Indiana University Press, 2005.

Derrida, Jacques, De la gramatología, trad. O. Del Barco y C. Ceretti, Mexico DF - Buenos Aires: Siglo XXI, 2003.

Derrida, Jacques, El animal que luego estoy si(gui)endo, trad. C. de Peretti y C. Rodríguez, Madrid: Trotta, 2008.

Foucault, M., L’herméneutique du sujet. Cours au Collège de France, 1982, Ed. Frédéric Gros, Seuil/Gallimard, 2001.

Foucault, M., "About the Beginning of the Hermeneutics of the Self. Two Lectures at Dartmouth”. Political Theory, vol. 21, n. 2, May 1993.

Foucault, M., "Prefacio a la transgresión", en De lenguaje y literatura, trad. Isidro Herrera, Barcelona: Paidós, 1996, pp. 123-142.

Foucault, M., "What is an Author?", Aesthetics, method and epistemology, edited by James D. Faubion, trad. Robert Huley, Londres: Penguin Press, 1998.

Foucault, M., Technologies of the Self. A seminar with Michel Foucault. Amherst (USA): The University of Massachusetts Press, 1988.

Garff, Joakim, "The Eyes of Argus: The Point of View and Points of View on Kierkegaard's Work as an Author”, Kierkegaard: A Critical Reader, ed. Jonathan Rée y Jane Chamberlain, Oxford: Blackwell Publishers..

Garff, Joakim, "Produire fut ma vie"- problèmes et perspectives de la biographie de Kierkegaard, Kierkegaard aujourd'bui. Recherches kierkegaardiennes au Danemark et en France, Editées et rédigées par Jacques Caron, Odense University Press: 1998.

Gutman, Huck, "Rousseau's Confessions: A Technology of the Self", Tecnologies of the Self. A Seminar with Michel Foucault. Amherst (USA): The University of Massachusetts Press, 1988.

Heidegger, Martin, The Concept of Time (1924), trans W. McNeill, Oxford: Blackwell and Cambridge University Press, 1992. [Heidegger, Gesamtausgabe: Phänomenologie des religiösen Lebens, vol. 60, section 2: "Augustinus un der Neoplatonismus, Haupteil,” p. 175 ff.].

Lyotard, Jean-François, The Confession of Augustine, Stanford, Calif.: Stanford University Press, 2000. 
Perarnau, Dolors, "El punto de vista sobre mi actividad como escritor: Tan solo un punto de vista", Kierkegaardiana, n. 23.

Revel, Judith, Foucault, un pensamiento de lo discontinuo, trad. Irene Agoff, Buenos Aires: Amorrotu, 2014.

Soderquist, Brian K., The Isolated Self, Copenhaguen: Reitzels, C.A., 2007.

Zambrano, María, La confesión: género literario y método, Madrid: Mondadori, 1988. 